\title{
Enabling Community Participation for Social Innovation in the Energy Sector
}

\author{
Ibnu Budiman ${ }^{1 *}$ \\ ${ }^{l}$ Wageningen University, Netherlands \\ Received November 27, 2017; Accepted August, 272018 \\ Available online 31 August 2018
}

\begin{abstract}
This study investigates enabling conditions for facilitating social innovation in the energy sector. This aspect is important to support the energy transition in Indonesia. This research provides appropriate project direction, including research (and action) gaps for the energy actors in Indonesia. The actors are encouraged to work further with the result of this study to stimulate the energy transition in Indonesia. This study uses a systemic change framework which recognizes four drivers of systemic change in a region: 1 . transforming political ecologies; 2. configuring green economies; 3. building adaptive communities; 4 . social innovation. These drivers are interconnected, and this study focuses on how the social innovation can be supported by other drivers. This study used interviews and literature review as the sources of data. There were interviews with eight experts who come from different countries and are experienced in social innovation in the energy sector. Afterward, this research reviewed related journal papers from the last five years, to check the latest developments within the topic, to support the interview results. The study found that the enabling condition can focus on one of the drivers of systemic change, which is building communities by increasing their participation, through several integrated actions. This point can be implemented in two types of citizen energy initiatives which are energy cooperatives and sustainable consumption initiatives. Further implementation of these initiatives requires a study on policy and governance support, to create complete enabling conditions to facilitate social innovation in the energy transition.
\end{abstract}

Keywords: Enabling condition, social innovation, renewable energy, citizen initiatives, community participation

\section{Introduction}

Since the end of the 20th century, the world has been paying increased attention to tackling the effects of climate change by aiming for a transition towards a system based on cleaner, renewable energy resources (Bulkeley \& Betsill, 2013). Due to this renewable-energy transition, we are facing many challenges such as the research and development of new clean energy technologies (Hisschemöller \& Sioziou, 2013). Besides this scientific and technological domain, it also affects political, societal, and economic issues (Akella et al., 2009; Mees et al., 2014).

In addressing societal issues, it is important to emphasize the involvement and role of citizens within the renewable-energy transition. It requires to focus on policy arrangements and social innovation. This idea is linked to the thought that making citizens part of the solution creates a sense of ownership. In theory, this could lead to an increased willingness of people to change behavior, become involved, and continue to remain in renewable-energy projects. Loorbach et al. (2008) show that involving citizens can prove difficult. After an initial phase of reduced energy consumption - by switching to energy-efficient technologies - stabilization took place (Loorbach et al., 2008). Further reductions in energy consumption were not easily achieved because of necessary changes in the direction of increased renewable energy production and decreased usage failed (Loorbach et al., 2008).

\footnotetext{
* Corresponding author

E-mail address: ibnu.budiman@wur.nl
} 
In Europe, there has been attention to social sciences and humanities aspects of the clean-energy transition (European Commission services, 2017, p. 106). It has identified socio-economic factors for the energy transition, which are; (1) pave the way for a positive public perception; (2) create longlasting and accepted governance arrangements; and (3) should generate both social and economic benefits (European Commission services, 2017, p. 106). These factors are relevant to challenges of renewable energy dissemination in Indonesia that need social innovation to tackle the barriers relate to abovementioned factors (Transrisk, 2017).

This research aims to bring the idea of social innovation in the energy sector to Indonesia. Therefore, the research question is: "What are the enabling conditions to facilitate social innovation in the energy sector?" There are many ideas on research questions for the upcoming project about social innovation, and an abundance of further research questions can be found in the relevant scholarly literature. This study helps to narrow the possible scope of the upcoming project by identifying the most promising research questions as identified by the experts. Thus, the conclusion of this study includes both possible research questions and strategy recommendations for working on the future project.

This paper is organized in the following way. After the introduction, part two introduces the conceptual framework. Therein some important concepts and definitions are given. It discusses the notions of systemic change, social innovation, and the renewable-energy transition. In part three on methodology, data collection and data analysis of this study are explained. Subsequently, part four presents results of an in-depth analysis of the possible project direction (including research and action gaps). In the following part, there is the discussion of the results about relevant literature and the possible list of research gaps. The discussion yields recommendations on the most promising research gaps and strategies for working on the future project. In the final part, the conclusion and a concise version of the recommendations are provided.

\section{Conceptual and Theoretical Framework}

This chapter explains the concepts and theories used in this paper. The first section looks at the energy transition. Section two analyses the concepts of systemic change and social innovation, that is required to support the renewable-energy transition. The section on systemic change also discusses Wolfram and Frantzeskaki's (2016) four drivers of systemic change.

\subsection{Energy Transition}

Davidsson (2014) defined energy transition as a fundamental structural change in the energy sector. It is caused by resource scarcity of petroleum supplies, high labor costs, and technological innovations and further stimulated by the increased intention for tackling the effects of climate change (Solomon, \& Krishna, 2011). Specifically, this context includes decentralized energy systems as part of an energy transition (Bulkeley \& Betsill, 2013).

Oberthür \& Roche (2008) considered the European Union (EU) as a leader on climate change policies. The EU has provided directions for the energy transition by picking up one of the topics: citizen engagement and consumers (European Commission, 2016). It aims to modernize the economy by enhancing economic activity in the renewable energy sector. It looks at transitioning from fossil fuels to renewable energy sources, enhancing energy efficiency, the creation of new governance arrangements, and rearranging the electricity market (European Commission, 2016).

Historically, the world has been applying the term 'clean energy' since the 1970s, and the term renewable energy gained momentum in the 1980s. Within the vision of a clean energy transition, there is a role for the process of carbon capture and storage, for example: the storage of carbon dioxide in depleted oil and gas reservoirs (Weber, 2016)). There is still a public discussion on the long-term implications of such technologies (Morris, 2017). Especially, since up until today projects that tried to implement these techniques, such as in the Netherlands- failed due to a lack of public acceptance (Ministry of Economic Affairs, Agriculture, and Innovation, 2010). 
Hisschemöller \& Sioziou (2013) argue that studying the enabling factors of past and present transitions is important for the acceleration of the renewable energy transition. They also find that one of these factors is research and development of new technologies. Others emphasize the importance of societal acceptance and economic issues in the renewable energy transition (Akella et al., 2009; Mees et al., 2014; Arent et al., 2017). Also, the creation of policies can facilitate the spread of already widely available renewable energy technologies (Oteman et al., 2017). Therefore, socio-economic factors such as private sector engagement and innovative approaches to policies and regulations, are needed as social system to support socio-technical transition to renewable energy.

\subsection{Systemic Change and Social Innovation}

A full renewable-energy transition requires a systemic change that includes macro-level innovations. This innovation consists of a series of technological advancements and changes in societies, their economic and social domains. As a result, the term social innovation emerges (Nicholls \& Murdock, 2012). The concept of social innovation can be a tool to analyze changes in social relations resulting from recent technological innovations. Nicholls \& Murdock (2012) assumed that the technological innovation not only affects the energy production and consumption, but also has (in)direct effects on consumers and the environment. Social innovation involves all sectors of society, i.e. public, private, and civil society actors (Nicholls \& Murdock, 2012; Miller et al., 2015).

\subsubsection{Systemic Change}

Coutard and Rutherford (2010) argue that social practices and the policies are essential to determine how socio-technical transitions play out (Coutard \& Rutherford, 2010). Examples of policies that shape social practices are subsidies on solar panels and sustainable housing policies (Coutard \& Rutherford, 2010). When these social practices and policies are not aimed at the transition, the chances of significant systemic change are reduced (Coutard \& Rutherford, 2010). In a more recent paper, both authors argue that urban clean-energy transitions are not the result of a change in the technical processes of energy consumption, distribution, and production (Rutherford \& Coutard, 2014). Instead, it depends on the combination of "how infrastructures, buildings, industries, institutions, as well as individuals and social groups, their practices and values both shape and are shaped by context-specific, conflicting energy needs, uses, and forms of management." (Rutherford \& Coutard, 2014, p. 1371) work together.

Wolfram and Frantzeskaki (2016) recognize four drivers of systemic change in cities. The first driver of systemic change looks at "transforming urban metabolisms and political ecologies" (Wolfram \& Frantzeskaki, 2016, p. 10). Coalitions of local governments, businesses, and citizens test new energy usages, technologies, and services to reduce the city's greenhouse gas emissions, maintain today's living standards, and sustain economic growth (Wolfram \& Frantzeskaki, 2016). A drawback of this driver are questions of legitimacy, openness, and accountability of the multi-level governance process (Wolfram \& Frantzeskaki, 2016).

The second driver is about "configuring urban innovation systems for green economies" (Wolfram \& Frantzeskaki, 2016 p. 10). Within this driver, particular attention is given to transformations of the production and consumption cycles of energy. It implies a focus on businesses and consumers, and their place-dependent networks, strategies, and requirements for creating a greener economy (Wolfram \& Frantzeskaki, 2016). Knowledge transfers and (social) innovations are facilitated through cooperation, e.g., by networks of actors with shared-values (Wolfram \& Frantzeskaki, 2016). In essence, systemic change takes place through cooperation that facilitates local (place-based) sociotechnical innovations in cities (Wolfram \& Frantzeskaki, 2016).

The third driver of systemic change is the "building of adaptive communities and ecosystems" (Wolfram \& Fratzeskaki, 2016, p. 11) and concerns the environmental effects of climate change on cities. A focus on ecosystem services is the result. Ecosystem services are the benefits that nature provides humans with, e.g., the cooling effects of vegetation/parks for neighboring buildings 
(Wolfram \& Fratzeskaki, 2016). This driver focuses on climate change adaptation (adaptive governance) within a multi-level and multi-sector governance framework (Wolfram \& Fratzeskaki, 2016). In short, public and private actors collaborate with each other.

The fourth driver is "empowering urban grassroots niches and social innovation" (Wolfram \& Fratzeskaki, 2016, p. 11). This driver focuses on the creation of new markets through the upscaling of successful grassroots initiatives (niches) (Wolfram \& Fratzeskaki, 2016). Eventually, these initiatives might be translated into local regulations and policies. In other words, cities can function as hubs for social innovation and grassroots initiatives (Wolfram, 2016).

There are complex interdependencies between various factors that influence social innovation (European Commission services, 2017, p. 106). Government and private interest groups have an opportunity to provide incentives for social innovation; this interdependence is also recognized by authors such as Miller et al., who argue that energy transitions nowadays go hand-in-hand with social, economic, and political shifts (Miller et al., 2015). Figure 1 shows that social innovations are interlinked with other drivers in the socio-energy systemic change, and it means that the systemic change also works as a driver supporting social innovation (Miller et al., 2015).

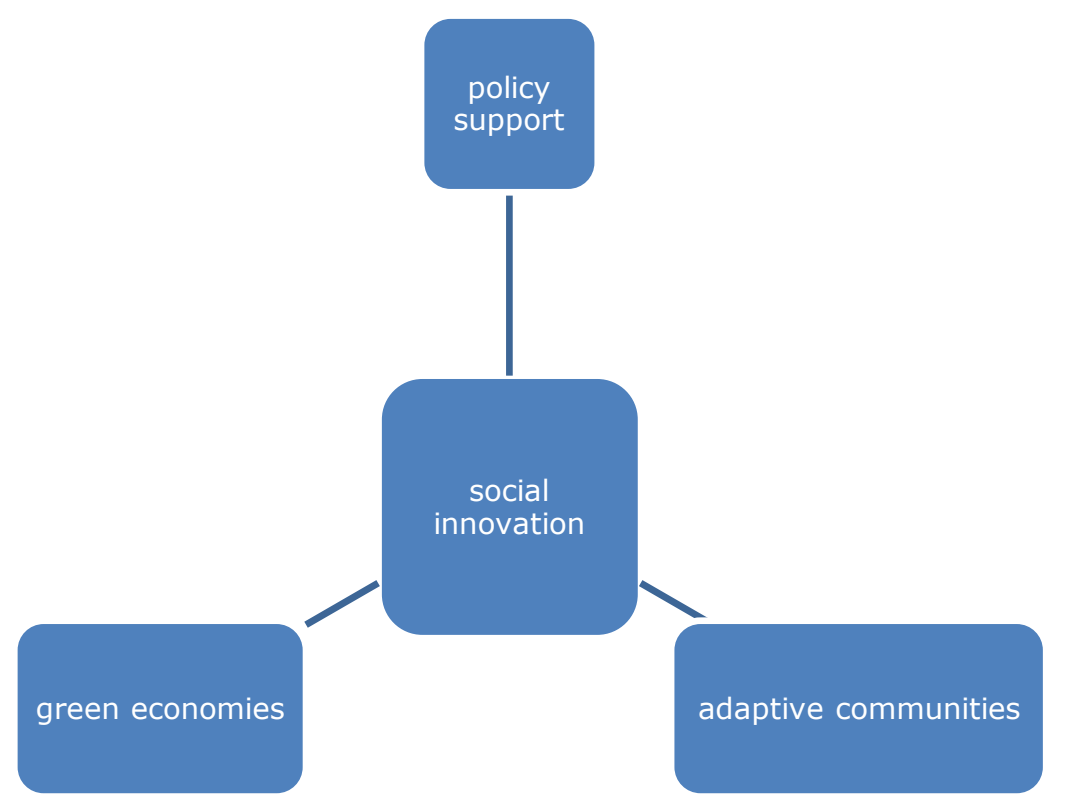

Figure 1. Drivers for social innovation

\subsubsection{Social Innovation}

Social innovation is various ways where people are coming up with new and more effective solutions and answers to problems such as climate change, energy, health, and poverty (Murray, et al. 2010). Social innovation acknowledges community participation. From the perspective of Wüstenhagen et al., high levels of participation reflect a community's acceptance of the social innovation (Wüstenhagen et al., 2007). Moreover, social innovation overlaps with business innovation. New business models on social innovation can result in profits in the form of livelihoods for local communities (Pol, 2009). A collaboration of civil society and business actors with government agencies can help provide incentives for social innovation (Miller et al., 2015). The incentives stimulate change in consumer behavior, which implies that social innovation needs to be inserted into an economic structure of interdependencies between multiple actors (Brand, 2008). Therefore, communities and citizens have a key role within the renewable-energy transition. By producing and consuming their energy, they can become active market players. Thus, multiple actors have to stimulate citizens' development from passive to pro-active consumers. In principle, when participants 
are closely engaged with energy production, they will have a higher awareness of their energy consumption (European Commission. 2016).

Social innovation in the energy sector takes place within the context of the decision-making process. Consumers are not isolated; they are inserted into an economic structure of interdependencies between the state, NGOs, science, media, and enterprises (Brand, 2008). Therefore, social innovation can only be studied in relation to these other actors. To understand and encourage the renewable-energy transition, it is necessary to study the context that surrounds consumers and stimulates systemic change. It is also necessary to make the connection with policy implementers and practitioners in the field (Arent et al., 2017). In many fields that study (environmental) behavior, it is a well-known phenomenon that often individuals who say they value sustainability, still behave in an unsustainable way [for an extensive overview of various analytical frameworks on this subject, see Kollmuss and Agyeman (2002)]. An ecological attitude does not necessarily lead to an increasing demand for ecological products (Claudy, 2013). Due to this attitude-behavior gap, studying actual practice or behavior is important in order to find out how to align individual behavior with the attitude.

\section{Methodology}

This research used a qualitative method by employing first-hand data from interviews and secondary data from the literature review.

\subsection{Data Collection}

In the interviews, this study implemented judgmental sampling to select the experts as our study population, because this non-probability sampling technique suits this research condition. Through own knowledge and professional judgment, this research chose units to be sampled (Kothari, 2004). In addition, this study also made use of snowball sampling by asking interviewees if they could recommend other topic-specific literature. A selection of these methods was used to meet the specific content of each sub-component. The combination of these methods forms an integrated analysis.

The research population consists of a total of eight experts from four research institutes, two NGOs, one company and one association. The reason behind this composition was to get balanced perspectives from academics, business professionals, and civil society representatives. Their expertise and backgrounds are all different. Some are more knowledgeable in the economic aspects of the renewable-energy transition, whilst others emphasize the transition's social and policy characteristics/requirements.

The in-depth interviews were semi-structured and were conducted with the eight experts. A characteristic of in-depth interviewing techniques is that there is repeated interaction between the researcher and the interviewee (Kumar, 2014). All interviews have been - with consent - recorded and/or transcribed. This research utilized this number of interviews to execute a Delphi technique. The Delpi approach was done to obtain information that may generate agreement on the enabling conditions of social innovation. The Delphi technique was adjusted to the project's needs. Conducting the first round of interviews is different from a common Delphi approach. Focus laid on finding out which approach suits to come up with a research gap. Additionally, not all experts answered all questionnaires. To get as many responses as possible, the flexibility of the questionnaires sequence was needed.

Delphi is a 'group communication' process, which uses a series of questionnaires (Hsu, 2007). An incorporated feedback mechanism is the starting point for the next interview and allows the interviewees to react on - anonymized - perspectives and answers of other experts (Linstone \& Turoff, 1975). In each round, the experts work separately from the group through a set of anonymized statements of the whole group. Anonymization gives the advantage of reducing the influence of dominant individuals (Hsu,2007). Finally, Delphi allows choosing between an oral or a written interview. That gives the right amount of flexibility to adjust the data collection methods towards the 
availability of the interviewees. Hence the interview can be time-consuming. Especially, when a questionnaire consists of a large number of statements (Hsu, 2007).

Another aspect of the qualitative method of this study was a literature review. It aims to understand the current state of research on the topic of social innovation in the energy sector. The online databases Scopus and Google Scholar were searched for relevant scientific papers. A method to enlarge the scope of the literature was to go through the references of already found articles. This literature review contributed to the discussion of the findings from the interviews.

The literature search was broadly over three categories, namely literature related to governance aspects, economic aspects, and social aspects. This categorization corresponds with the three elements of change that authors like (Miller et al. 2015) find highly important for a successful socio-energy system change. We selected the literature on the basis of relevance, and the main search was for papers of recent publication dates, starting with 2013.

\subsection{Data Analysis}

This study categorized or grouped responses of the first round of interview by the frequency/similarity of an answer on possible enabling conditions. This process aims to reduce the number to a manageable level, whilst keeping the essential meaning of responses. That was the basis for a wellstructured survey. The written interview asked for preference of possible research topics and reasons for the choice. The listed range of opinions - and their explanations - allow for an adjustment of the original opinion (Hsu, 2007). The purpose of this strategy was to make an individual interviewee aware of the viewpoints of other experts. According to the Delphi method, through questioning why certain strengths/opportunities are especially important, the answers are channelled into one specific direction (Linstone \& Turoff, 1975). Thereby, it is assumed that the judgment of multiple people is better than that of one individual (Linstone \& Turoff, 1975). Theoretically, the Delphi process can be continuously repeated until the experts agree on one direction.

The interviews formed the basis for the qualitative analysis, which is a commonly used tool in the social sciences. In this study, it is used for decision-making purposes to determine the focus of a future study. The interviews resulted in a list of more specific research topics that can be explored further. That information has to be prioritized. Going through each section, the items are discussed from the most to the least preferred in a logical way. Additionally, the preference from the interview can also change depending on the research topic.

The priority list of enabling conditions was used in order to look at future possibilities, by matching the topic with external trends (Chermack, 2007). The topic of social innovation is created by the discourse of experts. It has the influence on external trends - political, economic, social, technological, and competitive - factors (Chermack, 2007). To stimulate a new strategic initiative, the discourse and external factors are paired according to a systematic scheme (see Table 6). The strategy can be summed up as building on the exploration of the opportunities from the topic for future study (Dyson, 2004). Doing that, the analysis turns into actionable strategies to enable key decisions.

In presenting the result, this research takes a full advantage of the combination of the literature review and in-depth interviews.

\section{Result and Discussion}

This research found that there are three examples of social innovation in the energy sector, which are; prosumer initiatives, sustainable energy (consumption) community, and energy cooperatives.

A prosumer is a consumer that also produces energy, e.g. solar panels on one's roof. One such prosumer initiative is the Smart Grid project which facilitates bi-directional energy and information flow between the utility grid and the energy consumer (Rathnayaka, 2011). It allows the consumer to 
generate energy and to share it with other energy consumers throughout the grid (Rathnayaka, 2011). This kind of initiative is often associated with the idea of energy cooperatives. Cooperatives can foster and stimulate the development of local energy communities (Van Der Schoor \& Scholtens, 2015). In Indonesia, there have been several farmers cooperatives that support bioenergy dissemination. Such cooperatives can be developed further to become a social innovation in the energy sector (Transrisk, 2015).

Multiple actors should engage in the institutionalization and establishment of social innovation that supports the development of decentralized energy systems (Van Der Schoor \& Scholtens, 2015). For instance, in urban area, multiple cities support the Sustainable Development Goals that - amongst others - define the challenges of making cities and communities more sustainable, combat the effects of climate change, and ensure universal access to sustainable and renewable-energy resources (United Nations, 2015).

About 80 percent of interviewed experts prefer three main enabling conditions to facilitate social innovation in the energy sector, which are; 1 . increased community participation in citizen-led energy initiatives; 2. Cooperation with other energy actors to determine best practices and exchange experience to make policy recommendations; 3. existence of various levels of investment in the citizen energy initiatives. All three main preferences were analyzed in connection with relevant findings from the interviews and literature review.

The combination of the three preferences forms a type of the project, which combines elements of research and practice. The practical action can provide feedback which is fruitful for further research development. Some experts from the research institutes did also agree that the research should be connected with the programmes of the NGOs and/or consulting firms from the related field. They can help the researchers to determine best practices of initiatives in social innovation and to enable an exchange of experience among the initiatives. An NGO has to be ready to support this implementation and the practical part. Yet, there is a lack of experimental projects. (Hazel \& Onaga, 2003) studied experimental social innovation project and its dissemination. They argued that cross-project replication is necessary to examine projects that work in different settings of populations and costs. This result has potential to upgrade the effectiveness and quality of the project interventions. Action research on existing citizen initiatives is the concrete planning for the project development.

The combination of research and practice comes close to what might be a good project. Specific form is needed for the combination that fits the specific topic: enabling conditions to support social innovation in the renewable energy transition. This topic is one of three main preferences from the experts. They want the project to focus on the aspect of community participation in social innovation, particularly the strategy to increase the degree of participation. Instead of introducing new initiatives, they see expansion of existing initiatives through increased community participation as a good goal for social innovation in renewable energy. Future research can examine in detail different types of community participation. For example, it could compare non-members of community energy projects with the members, including the initiators of the projects.

Third preference of the experts is the effect of various levels of investment on social innovation success. This topic is the most interesting part of renewable energy transition because it leads to the idea of the prosumer initiative. The investment could be an incentive to increase the participation of the community, to be not just a consumer, but also a producer.

In addition, the multi-level effects of investment are important in making sure the social innovation is sustainable and transformative. The investment topic is connected with business models in energy cooperatives as a form of social innovation in the renewable energy transition. Energy cooperative is a common model for social innovation in the energy sector. A cooperative produces renewable energy from small-scale generation such as community-owned windfarms and biofuel projects. This initiative has a business model which is able to support economic development in the community (Huybrechts, \& Mertens, 2014). Possible future studies on this topic are coordinated actions among the 
cooperatives and their relation to other factors, as well as feasibility for upscaling the business model of the energy cooperatives.

From the main three preferences, the link to the governance is missing in those topics. Political context has to be explicitly mentioned in the project direction. Combination of the research project with practical contribution should be able to result in a useful policy recommendation. The policy recommendations for multi-level governance are necessary for one of the end products for the future project. This output helps social innovation to not only focus on local cohesiveness and its economic development but also to support the national political focus in commitment to sustainability discourses (Islar \& Busch, 2016).

One of the barriers in social innovation identified by Heaslip (et.al. 2016) is consideration of policy aspects. This issue was not deeply discussed in the interviews with the experts. Yet, it is slightly touched upon in the topic of governance and business models or economics. Based on the interconnected drivers of systemic change in cities (Wolfram \& Frantzeskaki, 2016), the three main preference topics from the experts are not sufficient as enabling conditions for supporting social innovation. Table 1 shows how the three preferences of enabling conditions connect with systemic change elements which work as drivers for social innovation. The topic of community participation fits with drivers from adaptive communities and topic of energy cooperative is related to green economies. Yet, citizen energy initiatives need to have one more driver of enabling conditions, which is policy and governance support. More specific research gaps need to be considered, as shown in Table 1.

Table 1. Main enabling conditions and its research gaps in systemic change to support social innovation

\section{Systemic change drivers to support social innovation}

\begin{tabular}{|l|l|l|l|l|}
\hline $\begin{array}{l}\text { Type of } \\
\text { project }\end{array}$ & $\begin{array}{l}\text { Connecting research with best practices, to enable an exchange of experiences and to } \\
\text { make policy recommendations }\end{array}$ \\
\hline $\begin{array}{l}\text { Drivers to } \\
\text { change }\end{array}$ & $\begin{array}{l}\text { Building adaptive } \\
\text { communities }\end{array}$ & $\begin{array}{l}\text { Configuring green } \\
\text { economies }\end{array}$ & $\begin{array}{l}\text { Transforming } \\
\text { ecologies }\end{array}$ & political \\
\hline $\begin{array}{l}\text { Topic of } \\
\text { project }\end{array}$ & $\begin{array}{l}\text { Increased degree of } \\
\text { community participation } \\
\text { and identifying new forms } \\
\text { of social innovation }\end{array}$ & $\begin{array}{l}\text { Multiplied effect of } \\
\text { various levels of } \\
\text { investment in the success } \\
\text { of social innovations }\end{array}$ & $\begin{array}{l}\text { Involvement of larger scale } \\
\text { political entities or policy } \\
\text { context for multi-level } \\
\text { governance }\end{array}$ \\
\hline
\end{tabular}

Research (and action) gaps

Lack of experimental projects

\begin{tabular}{|c|c|c|c|}
\hline $\begin{array}{l}\text { More } \\
\text { specific } \\
\text { research } \\
\text { topic }\end{array}$ & $\begin{array}{l}\text { - Influence of local } \\
\text { context } \\
\text { - Different types of } \\
\text { (people) participation } \\
\text { - Embedding the } \\
\text { participation into the } \\
\text { initiatives' } \\
\text { methodologies } \\
\text { - Characteristics and } \\
\text { performance measures } \\
\text { of the best initiatives }\end{array}$ & 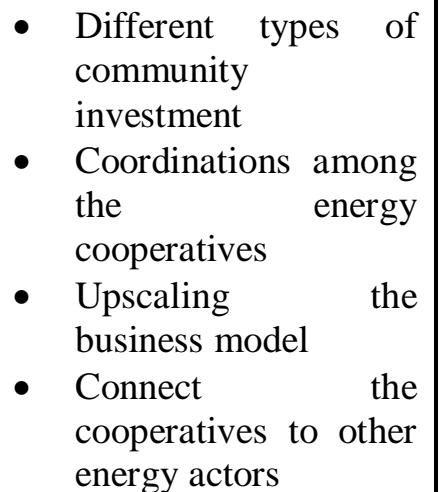 & $\begin{array}{l}\text { - Social network analysis of } \\
\text { related actors } \\
\text { - Conflicts within the } \\
\text { networks \& barrier to local } \\
\text { energy governance } \\
\text { - Institutionalization: } \\
\text { delivering policy, } \\
\text { organization } \\
\text { - Connect different } \\
\text { alternative (transition) } \\
\text { scenarios }\end{array}$ \\
\hline
\end{tabular}


The literature review found some topics or areas which can address insufficient information and knowledge about policy and governance support for citizen energy initiatives. In order to create effective policies and governance intervention for social innovation, we need to look at existing social network analysis among the actors or related stakeholders. Within the network, we can find various conflicts of interest among actors, which become a barrier to the development of citizen initiatives. Recognizing this issue can help a policy maker and/or future initiative to mitigate possible risks as an obstacle for institutionalizing enabling conditions for social innovation. The literature review suggests that the research gaps on policy and governance support based on three policy-making approaches: social network, conflict-barrier, and institutionalization (Mees, et.al 2014; Loorbach, et.al 2008).

In short, there is a possibility to combine above-mentioned preferences with existing research gaps as a strategy for the direction of the future action research. It can be started by focusing on one of the drivers of systemic change, which is building communities by increasing their participation. This can be implemented in two types of existing citizen energy initiatives which are energy cooperatives and sustainable consumption initiatives. It also requires a study on its related policy and governance support, in order to create complete enabling conditions to facilitate social innovation in renewable energy transition. More broadly, currently there is a lack of overview on social innovation projects. Therefore, a cross-case comparison of different projects and exchange of experience between them are necessary.

Once all the gaps are studied further and the result is found, topics from Table 1 will work as the roadmap to plan a policy of social innovation in the energy sector in Indonesia.

\section{Conclusions and Recommendations}

To support social innovation in the clean energy transition, it is necessary to emphasize the involvement and role of citizens within the renewable-energy initiatives. The citizen energy initiatives work as social innovation in the energy sector. Our findings argue that citizen energy initiatives are linked to the thought that a sense of ownership makes citizens a part of the solution. It can be enabled by increasing citizen participation in existing citizen energy initiatives, collaborating with business actors, and stimulating policy and governance arrangements that can support the initiatives. It triggers the systemic change that supports willingness of people to change behavior and participate in renewable-energy projects over a long term. To get to this point, this is a list of recommendations for energy actors (companies, NGOs, local cooperatives, farmers group, the ministries, and the local governments) in Indonesia:

- To combine research and practice in one project, such as; (community-based) participatory action research, applied research or citizen science

- The topic of the project can focus on increasing community participation in existing citizen energy initiatives such as energy cooperatives and sustainable energy consumption projects.

- To include study of policy and governance support to stimulate community participation in the citizen energy initiatives

- To be aware of the different local contexts in designing the project and ultimately in carrying out the project, and to provide policy advice on this issue.

- To include local actors and possibility for transfer of experience between different countries

\section{References}

Akella, A. K., Saini, R. P., \& Sharma, M. P. (2009). Social, economic and environmental impacts of renewable energy systems. Renewable Energy, 34(2), 390-396.

Arent, D., Arndt, C., Miller, M., Zinaman, O., \& Tarp, F. (Eds). (2017). The Political Economy of Clean Energy Transitions. Oxford, United Kingdom: Oxford University Press.

Bauwens, T., Gotchev, B., \& Holstenkamp, L. (2016). What drives the development of community energy in Europe? The case of wind power cooperatives. Energy Research \& Social Science, 13, 136-147. 
Brand, K. W. (2008). Konsum im Kontext. Der „,verantwortliche Konsument “-ein Motor nachhaltigen Konsums. Nachhaltigkeit als radikaler Wandel. Die Quadratur des Kreises, 71-93.

Bulkeley, H., \& Betsill, M. M. (2013). Revisiting the urban politics of climate change. Environmental Politics, 22(1), 136-154.

Chermack, T. J., \& Kasshanna, B. K. (2007). The use and misuse of SWOT analysis and implications for HRD professionals. Human Resource Development International, 10(4), 383-399.

Claudy, M. C., Peterson, M., \& O’Driscoll, A. (2013). Understanding the attitude-behavior gap for renewable energy systems using behavioral reasoning theory. Journal of Macromarketing, 33(4), 273-287.

Coutard, O., \& Rutherford, J. (2010). Energy transition and city-region planning: understanding the spatial politics of systemic change. Technology Analysis \& Strategic Management, 22(6), 711727.

Davidsson, S. (2014). Global Energy Transitions: A Comparative Analysis of Key Countries and Implications for the International Energy Debate. World Energy Council, Weltnerergierat: Berlin, Germany.

Dyson, R. G. (2004). Strategic development and SWOT analysis at the University of Warwick. European journal of operational research, 152(3), 631-640.

European Commission services. (2017). Horizon 2020 - Secure, clean and efficient energy (Version 19 May 2017).

European Commission. (2016). Clean Energy For All Europeans (COM(2016) 860 final). Retrieved from http://eur-lex.europa.eu/resource.html?uri=cellar:fa6ea15b-b7b0-11e6-9e3c-01 aa75ed71a 1.0001.02/DOC_1\&format=PDF

European Commission. (n.d.). Secure, Clean and Efficient Energy - European Commission. Retrieved October 16, 2017, from https://ec.europa.eu/programmes/horizon2020/en/h2020-section/secureclean-and-efficient-energy

Hand, E. (2010). People power. Nature, 466(7307), 685.

Hazel, K. L., \& Onaga, E. (2003). Experimental social innovation and dissemination: The promise and its delivery. American Journal of Community Psychology, 32(3-4), 285-294.

Heaslip, E., Costello, G. J., \& Lohan, J. (2016). Assessing good-practice frameworks for the development of sustainable energy communities in Europe: lessons from Denmark and Ireland. Journal of Sustainable Development of Energy, Water and Environment Systems, 4(3), 307-319.

Hielscher, S., Seyfang, G., \& Smith, A. (2011). Community innovation for sustainable energy (No. 2011-03). CSERGE Working Paper.

Hisschemöller, M., \& Sioziou, I. (2013). Boundary organizations for resource mobilization: enhancing citizens' involvement in the Dutch energy transition. Environmental Politics, 22(5), $792-810$.

Hsu, C. C., \& Sandford, B. A. (2007). The Delphi technique: making sense of consensus. Practical assessment, research \& evaluation, 12(10), 1-8.

Huybrechts, B., \& Mertens, S. (2014). The relevance of the cooperative model in the field of renewable energy. Annals of Public and Cooperative Economics, 85(2), 193-212.

Islar, M., \& Busch, H. (2016). "We are not in this to save the polar bears!"-the link between community renewable energy development and ecological citizenship. Innovation: The European Journal of Social Science Research, 29(3), 303-319.

Kollmuss, A., Agyeman, J. (2002). Mind the Gap: Why do people act environmentally and what are the barriers to pro-environmental behavior?. Environmental Education Research, 8(3), 239-260.

Kumar, R. (2014). Research Methodology: A step-by-step guide for beginners. London: Sage Publications.

Linstone, H. A., \& Turoff, M. (Eds.). (1975). The Delphi method: Techniques and applications (Vol. 29). Reading, MA: Addison-Wesley.

Loorbach, D., Van der Brugge, R., \& Taanman, M. (2008). Governance in the energy transition: Practice of transition management in the Netherlands. International Journal of Environmental Technology and Management, 9(2-3), 294-315.

Mees, H. L. P., Dijk, J., Van Soest, D., Driessen, P. P. J., Van Rijswick, M. H. F. M. W., \& Runhaar, H. (2014). A method for the deliberate and deliberative selection of policy instrument mixes for climate change adaptation. Ecology and Society, 19(2). 
Miller, C., Richter, J., O'Leary, J. (2015). Socio-energy systems design: A policy framework for energy transitions. Energy Research \& Social Science. 6, 29-40.

Ministry of Economic Affairs, Agriculture, and Innovation. (2010, November 4). CO2-opslagproject Barendrecht van de baan | Nieuwsbericht | Rijksoverheid.nl. Retrieved October 11, 2017, from https://www.rijksoverheid.nl/actueel/nieuws/2010/11/04/co2-opslagproject-barendrecht-van-debaan

Morris, C. (2017, January 30). Clean energy or renewable energy? The label matters! - Energy transition. Retrieved October 10, 2017, from https://energytransition.org/2017/01/clean-energyor-renewable-energy-the-label-matters/

Murray, R., Caulier-Grice, J., \& Mulgan, G. (2010). The open book of social innovation. London: National endowment for science, technology and the art.

Nicholls, A., \& Murdock, A. (2012). The nature of social innovation. In Social innovation (pp. 1-30). Palgrave Macmillan UK.

Oberthür, S., \& Roche Kelly, C. (2008). EU leadership in international climate policy: achievements and challenges. The International Spectator, 43(3), 35-50.

Oteman, M., Kooij, H. J., \& Wiering, M. A. (2017). Pioneering renewable energy in an economic energy policy system: the history and development of Dutch grassroots initiatives. Sustainability, 9(4), 550.

Pacheco-Torgal, F. (2014). Eco-efficient construction and building materials research under the EU Framework Programme Horizon 2020. Construction and building materials, 51, 151-162.

Pol, E., \& Ville, S. (2009). Social innovation: Buzz word or enduring term?. The Journal of SocioEconomics, 38(6), 878-885.

Rathnayaka, A. D., Potdar, V. M., Hussain, O., \& Dillon, T. (2011, December). Identifying prosumer's energy sharing behaviours for forming optimal prosumer-communities. In Cloud and Service Computing (CSC), 2011 International Conference on (pp. 199-206). IEEE.

Rutherford, J., \& Coutard, O. (2014). Urban Energy Transitions: Places, Processes and Politics of Socio-technical Change. Urban Studies, 51(7), 1353-1377.

Solomon, B. D., \& Krishna, K. (2011). The coming sustainable energy transition: History, strategies, and outlook. Energy Policy, 39(11), 7422-7431.

TRANSrisk. (2017). Report on Social Discourse Analyses and Social Network Analyses Retrieved from https://europa.eu/capacity4dev/public-energy/documents/transrisk-report-report-socialdiscourse -analyses-and-social-network-analyses

United Nations. (2015). Sustainable development goals - United Nations. Retrieved September 27, 2017, from http://www.un.org/sustainabledevelopment/sustainable-development-goals/

Van Der Schoor, T., \& Scholtens, B. (2015). Power to the people: Local community initiatives and the transition to sustainable energy. Renewable and Sustainable Energy Reviews, 43, 666-675.

Weber, T. (2016, December 9). Sauber argumentiert - Energiewende - Erneuerbare Energien. Retrieved October 10, 2017, from https://www.erneuerbareenergien.de/sauberargumentiert/150/437/99569

Wolfram, M., \& Frantzeskaki, N. (2016). Cities and systemic change for sustainability: Prevailing epistemologies and an emerging research agenda. Sustainability, 8(2), 144.

Wüstenhagen, R., Wolsink, M., \& Bürer, M. J. (2007). Social acceptance of renewable energy innovation: An introduction to the concept. Energy policy, 35(5), 2683-2691. 